\title{
ANÁLISE SENSORIAL DE CERVEJAS ELABORADAS COM MEL
}

\section{SENSORY ANALYSIS OF BEER PRODUCED WITH HONEY}

\author{
Luciana Trevisan Brunelli ${ }^{1}$; Waldemar Gastoni Venturini Filho². \\ ${ }^{1,2}$ Faculdade de Ciências Agronômicas-FCA-Universidade Estadual Paulista - UNESP - Botucatu - Brasil - \\ lutbrunelli@gmail.com
}

\begin{abstract}
Resumo
O objetivo deste trabalho foi produzir e analisar sensorialmente cervejas utilizando mel como adjunto de malte. Os tratamentos originaram-se de um fatorial $3 \times 3$ proveniente da combinação de três concentrações de extrato primitivo $\left(11,13\right.$ e $15^{\circ}$ Brix) e três porcentagens de mel na formulação do mosto (0 20 e 40\%). A mosturação foi realizada pelo processo de infusão, sendo o mel adicionado na etapa de fervura. Depois de clarificado, o mosto teve seu teor de extrato corrigido e foi inoculado com levedura de baixa fermentação. A fermentação ocorreu a $10{ }^{\circ} \mathrm{C}$. A cerveja foi engarrafada manualmente e armazenada em freezer à temperatura de $0{ }^{\circ} \mathrm{C}$ por 15 dias, para a sua maturação. A análise sensorial foi realizada por meio do teste de escala hedônica estruturada de nove pontos. Os atributos sensoriais analisados foram aparência, aroma, sabor e avaliação global. Os resultados obtidos, para cada atributo, foram submetidos à análise de variância para experimento inteiramente casualizado. Todas as cervejas elaboradas foram aprovadas pela equipe sensorial, sendo que a presença de mel na formulação das cervejas comuns $\left(11^{\circ}\right.$ Brix) e extra $\left(13^{\circ}\right.$ Brix) não interferiu na aceitação dos provadores para todos os atributos sensoriais avaliados. Entretanto, as cervejas fortes com mel em sua composição obtiveram maior aceitação dos provadores.
\end{abstract}

Palavras-chave: bebida alcoólica; escala hedônica; teste de aceitação.

\section{Introdução}

A legislação brasileira define cerveja como sendo “... a bebida obtida pela fermentação alcoólica do mosto cervejeiro oriundo do malte de cevada e água potável, por ação da levedura, com adição de lúpulo" (BRASIL, 2009). Parte do malte de cevada poderá ser substituída por adjuntos cervejeiros, cujo emprego não poderá ser superior a $45 \%$ em relação ao extrato primitivo, isto é, extrato do mosto de malte de origem da cerveja.

O mel é um ingrediente versátil e altamente fermentescível, com sabor e aroma característicos, atribuindo sabor diferenciado à bebida ou alimento (CRANE, 1987). A adição de 
mel em cerveja proporciona uma bebida menos encorpada e aumenta a quantidade de álcool, além de uma sensação alcoólica suave se comparada à cerveja com açúcar comum (SMITH, 2009). O mel é responsável por fornecer notas florais de aroma à cerveja, por meio dos polens e néctares utilizados pelas abelhas na sua produção.

$\mathrm{Na}$ cerveja, o mel garante uma doçura residual e um leve aroma característico, tornando-a uma bebida voltada ao público feminino. Esse tipo de cerveja deve ser pouco lupada, e mais forte, com 13 a $15 \%$ de extrato primitivo, com a finalidade de aumentar o caráter vinoso da bebida, por meio do maior teor de álcool e ésteres (KUNZE, 2006).

Alguns países, como a Canadá, Inglaterra, Estados Unidos e Argentina, comercializam cervejas com mel, o que indica o grande potencial desse ingrediente na elaboração da bebida. A cervejaria inglesa Fuller's produz a Honey Dew, a microcervejaria argentina Buller produz artesanalmente sete tipos de cerveja, entre elas a Honey Beer. A cervejaria brasileira Colorado, comercializa uma cerveja feita com trigo e mel. No Canadá há várias cervejas com mel, entre elas a Boréale Dorée, Granville Island Cypress Honey Lager, Miel Pilsner e Shaftebury Honey Pale Ale e nos Estados Unidos há Blue Moon Honey Blonde.

No ranking de cervejas do site Brejas (http://www.brejas.com.br), os avaliadores de cervejas relatam que a inglesa Fuller’s Honey Drew possui uma coloração dourada, apresenta baixa turbidez, espuma branca e é bem carbonatada. O aroma de mel está presente em destaque, é pouco amarga e o sabor de mel é evidente. Uma belíssima cerveja, bem diferente das cervejas tradicionalmente encontradas no mercado (BREJAS, 2008a). Já cerveja chilena Kunstmann Miel da Cerveceria Valdivia, apresenta coloração dourada escura, carbonatação média e espuma de coloração bege. $\mathrm{O}$ mel é muito predominante no aroma e sabor, e devido à baixa intensidade do amargor resulta em uma cerveja enjoativa (BREJAS, 2008b).

A cerveja fabricada com mel pode ter seus atributos sensoriais cientificamente caracterizados por meio da análise sensorial.

Segundo a Associação Brasileira de Normas Técnicas (1993), análise sensorial é definida como: “... a disciplina científica usada para evocar, medir, analisar e interpretar reações das características dos alimentos e materiais como são percebidos pelos sentidos: visão, olfato, gosto, tato e audição".

Os métodos de análise sensorial são classificados em discriminativos, afetivos e descritivos. Os métodos discriminativos (ou de diferença) são empregados quando há necessidade de avaliar a existência de diferença sensorial entre duas ou mais amostras, em termos globais ou em um atributo específico; são indicados para testar diferença quando ocorre mudança no produto, como alteração de formulação ou mudança no processamento, para isso é necessária uma equipe de provadores selecionados com conhecimento técnico. Os métodos afetivos são utilizados para avaliarem a 
aceitação ou preferência pelo produto. Diferente do anterior, os avaliadores não precisam de treinamento e são indicados quando há o desenvolvimento de novos produtos ou até mesmo para comparar produtos concorrentes. Os métodos descritivos têm caráter qualitativo e quantitativo, pois avaliam e descrevem a intensidade dos atributos sensoriais dos alimentos e bebidas e necessitam de equipes de avaliadores selecionados e treinados (BEHRENS, 2011; DUTCOSKY, 2011).

A escala hedônica é o método afetivo mais empregado devido ao caráter informativo de seus resultados. A escala numérica estruturada de nove categorias foi a primeira versão desenvolvida desse método, seguida da escala linear de 9 ou $10 \mathrm{~cm}$. Esse método de avaliação sensorial é utilizado quando pretende efetuar testes entre mais de um produto, sendo possível deduzir a preferência dos consumidores. Os dados obtidos por meio da escala hedônica mista numérica podem ser resumidos na forma de médias, e comparados estatisticamente por análise de variância, teste de Tukey, teste $t$ de student, etc (BEHRENS, 2011).

De acordo com Rodrigues e Iemma (2009), "Experimentos delineados em esquemas fatoriais são aqueles que envolvem combinações entre os níveis de dois ou mais fatores”. Assim os tratamentos com dois ou mais fatores (tratamento) em dois ou mais níveis (doses) são chamados

fatoriais. Nos esquemas fatoriais cada combinação se torna um tratamento. Esses experimentos são vantajosos no estudo da interação entre os tratamentos, sendo utilizados em estudos com drogas terapêuticas, aditivos químicos, de fertilizantes etc (RODRIGUES e IEMMA, 2009).

A relação entre o produto e o consumidor se estabelece por intermédios das características organolépticas identificadas por análise sensorial. A qualidade sensorial das cervejas é a soma das características que possibilitam atrair e satisfazer os consumidores, sendo o aroma e sabor fatores decisivos da qualidade do produto. Portando, há necessidade de medir a qualidade sensorial para melhor conhecer e controlar o aroma e sabor no produto. As qualidades ou os defeitos memorizados pelo consumidor determinam sua atitude a este ou aquele produto (DRAGONE; ALMEIDA e SILVA, 2010).

\section{Material e Métodos}

\section{Planejamento experimental}

O delineamento experimental utilizado foi inteiramente casualizado com nove tratamentos e duas repetições. Os tratamentos originaram-se de um fatorial 3x3 proveniente da combinação de três concentrações de extrato primitivo $\left(11,13\right.$ e $15^{\circ}$ Brix $)$ e três porcentagens de mel na formulação do mosto $(0,20$ e $40 \%)$. 


\section{Elaboração da cerveja}

O malte $(4 \mathrm{~kg})$ foi moído em moinho de dois rolos e em seguida mosturado na presença de 12 kg de água da rede pública duplamente filtrada (celulose e carvão ativo) pelo processo de infusão, conforme Figura 1. Ao final da mosturação realizou-se o teste de iodo, para confirmação da sacarificação do amido.

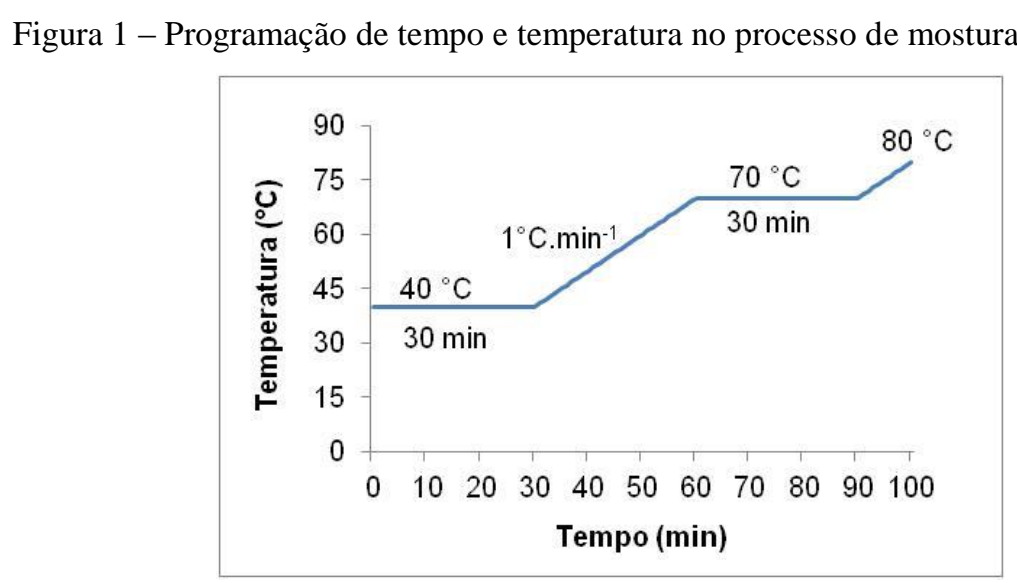

Na tina de mosturação, equipada com fundo falso ranhurado, o mosto (primário) foi separado do bagaço do malte por meio de filtração convencional, sob pressão atmosférica, sendo a própria torta de filtração (bagaço de malte) usada como elemento filtrante. Após a filtração do mosto primário, a torta foi lavada com $8 \mathrm{~kg}$ de água $\left(80{ }^{\circ} \mathrm{C}\right)$, para extração do açúcar residual, obtendo-se o mosto secundário. A mistura de ambos (mosto misto) foi fervida $\left( \pm 100^{\circ} \mathrm{C}\right)$ à pressão atmosférica durante 60 minutos. O lúpulo foi adicionado pelo método das três cargas (HUDSTON, 1977), sendo que aos 15 minutos de ebulição, foi adicionado 1 g lúpulo (tipo amargor) em péletes; a segunda carga ( $2 \mathrm{~g}$ ) foi adicionada aos 30 minutos e a última $(1 \mathrm{~g})$ foi feita aos 45 minutos. Após a última carga de lúpulo, o mel de laranjeira foi adicionado ao mosto na proporção de 0, 20 e 40\%, com base no extrato, sendo sua quantidade calculada a partir das equações 1 e 2 .

$$
\% \text { de mel }=\left(\frac{\text { Mextrato mel }}{\text { M extrato mel }+ \text { M extrato malte }}\right)-100
$$

Onde:

$\%$ de mel $=$ percentual de mel na formulação, na base do extrato;

M extrato mel = massa de extrato de mel; 
M extrato malte $=$ massa de extrato de malte.

A massa de extrato de mel foi convertida em massa de mel pela fórmula matemática que define Brix (Equação 2):

$$
\text { Brix }=\frac{\text { Mextrato mel }}{\text { Mmel }}-100
$$

Onde:

Brix = teor de extrato do mel;

M extrato mel = massa de extrato do mel;

M mel = massa de mel a ser adicionada ao mosto de malte.

O mosto depois de clarificado teve o seu teor de extrato corrigido para 11,13 e $15^{\circ}$ Brix, através da adição de água, conforme equação 3.

$$
\mathrm{B} 1 * \mathrm{M} 1+\mathrm{B}_{2} * \mathrm{M}_{2}=\mathrm{B}_{3} * \mathrm{M}_{3}
$$

Onde:

$\mathrm{B}_{1}=$ Brix do mosto inicial;

$\mathrm{M}_{1}=$ massa do mosto inicial;

$\mathrm{B}_{2}=$ Brix da água;

$\mathrm{M}_{2}=$ massa de água;

$\mathrm{B}_{3}=$ Brix do mosto final;

$\mathrm{M}_{3}=$ massa do mosto final.

Para a inoculação, utilizou-se levedura cervejeira de baixa fermentação da espécie Saccharomyces cerevisiae, centrifugada (4000 rpm / $5 \mathrm{~min}$ ) na proporção de $1 \% \mathrm{~m} / \mathrm{m}$. Antes da inoculação, $200 \mathrm{~mL}$ de mosto corrigido foi separado e inoculado com aproximadamente $20 \mathrm{~g}$ de fermento cervejeiro centrifugado e colocado para fermentar em temperatura ambiente até a estabilização do teor de extrato (atenuação limite). A fermentação foi acompanhada diariamente, até o mosto apresentar o valor de $1{ }^{\circ}$ Brix acima da atenuação limite. As cervejas foram envasadas manualmente em garrafas de $600 \mathrm{~mL}$ e colocadas em freezer, na temperatura de $0{ }^{\circ} \mathrm{C}$, por 15 dias, 
para maturação. A carbonatação ocorreu na própria garrafa, através da fermentação do açúcar residual presente na cerveja, por ação de leveduras remanescentes.

\section{Análise sensorial}

A análise sensorial foi realizada por meio do teste de aceitação, na qual se avaliou os atributos: aparência, aroma, sabor e avaliação global. Para efetuar a avaliação, dos atributos das cervejas, empregou-se a escala hedônica estruturada de nove pontos variando de 1 - "desgostei extremamente" a 9 - "gostei extremamente" (BRASIL, 2005; BEHRENS, 2011).

O painel sensorial contou com 60 provadores não selecionados e não treinados de ambos os sexos, na faixa etária de 18 a 50 anos. Para cada provador, serviram-se $50 \mathrm{~mL}$ de cerveja na temperatura aproximada de $5^{\circ} \mathrm{C}$, em copos de vidro transparentes; água mineral e biscoito de água e sal. Foram avaliados no teste os seguintes atributos: aparência, aroma, sabor e avaliação global (BEHRENS, 2011).

\section{Análise Estatística}

Os dados obtidos, para cada atributo sensorial avaliado, foram submetidos à análise de variância para experimento inteiramente casualizado no arranjo fatorial $3 \times 3$, conforme Vieira (2006). Foram calculadas as estatísticas F e p para verificar efeito de tratamento. As médias dos tratamentos foram comparadas pelo teste de Tukey ao nível de 5\% com o auxílio do software estatístico SISVAR (FERREIRA, 2011).

\section{Resultados e Discussão}

Os valores médios dos atributos analisados (aparência, aroma, sabor e avaliação global) da cerveja comum $\left(11^{\circ}\right.$ Brix $)$, cerveja extra $\left(13^{\circ}\right.$ Brix $)$ e cerveja forte $\left(15^{\circ}\right.$ Brix $)$ elaboradas com 0,20 e $40 \%$ de mel, estão apresentadas na Tabela 1. 
Tabela 1 - Média das notas da análise sensorial para os atributos: aparência, aroma, sabor e avaliação global

\begin{tabular}{ccccc}
\hline $\begin{array}{c}\text { Concentração de } \\
\text { extrato primitivo }\end{array}$ & Atributos & \multicolumn{3}{c}{ Porcentagem de mel na formulação do mosto } \\
\hline \multirow{2}{*}{$\mathbf{1 1}{ }^{\circ}$ Brix } & Aparência & 6,68 & $\mathbf{2 0 \%}$ & $\mathbf{4 0 \%}$ \\
& Aroma & 6,72 & 6,47 & 6,92 \\
& Sabor & 5,93 & 6,25 & 6,15 \\
& Avaliação Global & 6,37 & 5,73 & 6,38 \\
& Aparência & 6,13 & 6,15 & 6,63 \\
\hline \multirow{2}{*}{$\mathbf{1 3}^{\circ}$ Brix } & Aroma & 6,15 & 6,35 & 6,5 \\
& Sabor & 5,6 & 6,08 & 5,92 \\
& Avaliação Global & 6,03 & 5,83 & 6,13 \\
& Aparência & 5,88 & 6,18 & 6,33 \\
\hline \multirow{2}{*}{${ }^{\circ}$ Brix } & Aroma & 5,65 & 6,58 & 6,75 \\
& Sabor & 5,45 & 6,55 & 6,67 \\
& Avaliação Global & 5,68 & 6,57 & 6,63 \\
\hline
\end{tabular}

As cervejas foram aprovadas pela equipe sensorial (Tabela 1), obtendo-se em média a nota 6,37 para cerveja comum, 6,10 para a cerveja extra e 6,32 para a cerveja forte. Em relação às diferentes porcentagens de mel, as cervejas obtiveram em média a nota 6,02 para cervejas com $0 \%$ de mel; 6,29 para 20\% e 6,48\% para 40\%. Médias entre 6 e 7 significam que a equipe classificou sensorialmente as cervejas entre "gostei ligeiramente" a "gostei regularmente" (BEHRENS, 2011).

O motivo pelo qual os provadores atribuíram notas entre 6 e 7 pode ser devido ao padrão de referência que existe em suas mentes, ou seja, as cervejas industriais do tipo Pilsen. Enquanto as Pilsen industriais são filtradas e pasteurizadas, o inverso aconteceu com as cervejas produzidas no presente estudo, resultando em notas abaixo do esperado.

Tabela 2 - Significâncias estatísticas obtidas pelo teste F para os atributos: aparência, aroma, sabor e avaliação global.

\begin{tabular}{|c|c|c|c|}
\hline Parâmetros & $\begin{array}{l}\text { Concentração de } \\
\text { extrato primitivo } \\
\left(11,13 \text { e } 15^{\circ} \text { Brix }\right) \\
\end{array}$ & $\begin{array}{l}\text { Porcentagem de mel } \\
\quad(0,20 \text { e } 40 \%)\end{array}$ & $\begin{array}{c}\text { Interação extrato } \\
\text { primitivo } x \text { porcentagem } \\
\text { de mel } \\
\end{array}$ \\
\hline Aparência & Ns & $* *$ & Ns \\
\hline Aroma & Ns & Ns & $* *$ \\
\hline Sabor & Ns & $* *$ & Ns \\
\hline Avaliação global & Ns & $* *$ & $* *$ \\
\hline
\end{tabular}

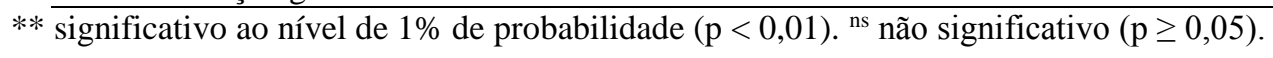

\section{Atributo Aparência}

A adição de mel (Tabela 2) interferiu significativamente na aparência das bebidas ( $\mathrm{p}=$ 0,0240). A média das notas para o atributo aparência das cervejas elaboradas com $40 \%$ mel e a das cervejas puro malte $(0 \%$ de mel) foram significativamente diferentes (Figura 2). Esse 
comportamento pode ser devido a maior carbonatação e a maior presença de espuma nas cervejas com mel, além disso, a adição dessa matéria-prima diminui a turbidez, promovendo uma melhor clarificação, além de diminuir a intensidade de cor da cerveja (BRUNELLI, 2012).

Figura 2 - Médias dos resultados do atributo aparência em relação à porcentagem de mel

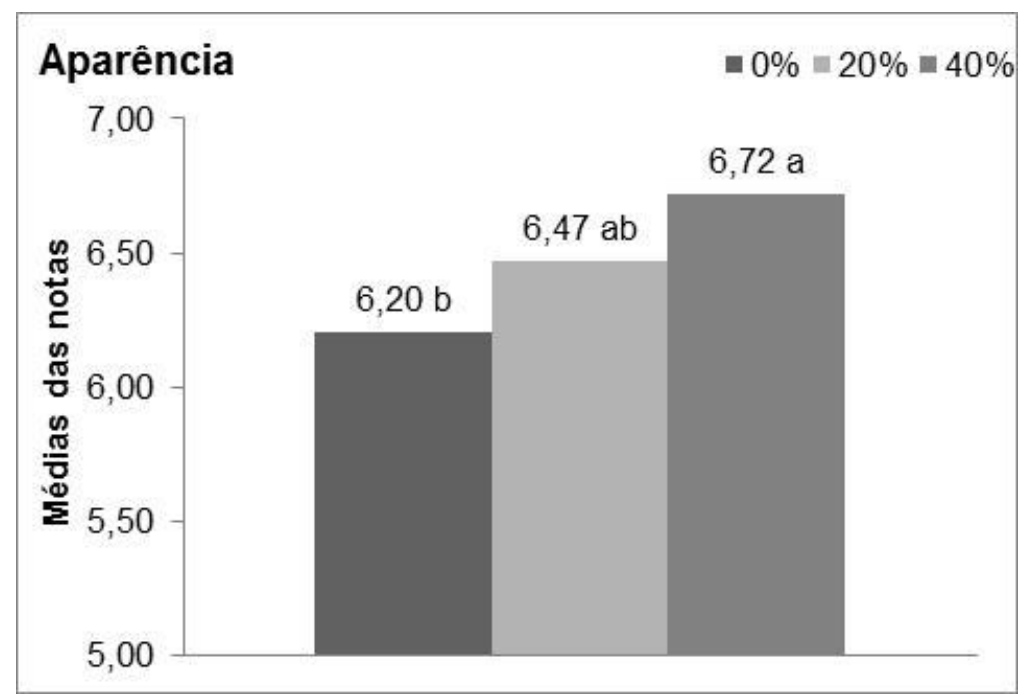

\section{Atributo Aroma}

No atributo aroma, a interação entre as diferentes porcentagens de mel na formulação das cervejas $(0,20$ e $40 \%)$ e as diferentes concentrações de extrato no mosto $\left(11,13\right.$ e $15^{\circ}$ Brix $)$ foi significativa para este atributo avaliado $(\mathrm{p}=0,0029)$ (Tabela 2$)$, em função disso efetuou-se a análise do desdobramento da porcentagem de mel dentro de cada nível da concentração do mosto e a análise do desdobramento da concentração do mosto dentro de cada nível da porcentagem de mel.

O efeito da porcentagem de mel no aroma das cervejas foi apenas significativo nas bebidas elaboradas com mosto a $15^{\circ}$ Brix $(\mathrm{p}=0,0025)$. Nas cervejas fortes (Figura 3-A), as bebidas elaboradas com mel apresentaram médias superiores em relação a puro malte. As cervejas fortes carregam mais mel em sua composição, por isso, é provável que os componentes aromáticos dessa matéria-prima tenham sido mais facilmente percebidos pelos provadores, pois estavam em maior concentração nesse tipo de bebida.

O efeito da concentração do mosto dentro das diferentes proporções de mel só foi significativo nas cervejas elaboradas com $0 \%$ de mel $(p=0,004)$. Com o aumento da concentração 
de extrato no mosto, as médias das notas das cervejas puro malte decrescem (Figura 3-B), demonstrando que os provadores prefeririam as cervejas com odor mais brando de malte. Esse comportamento pode estar relacionado ao padrão de referência do painel de provadores. As cervejas comerciais do tipo Pilsen são as mais disponíveis e consumidas no mercado nacional (SOARES, 2011), e a maioria delas são fabricadas com malte e adjuntos a base de milho e arroz que abrandam as características sensoriais da cerveja, como o aroma, o sabor e a intensidade de cor (ARAÚJO; SILVA; MINIM, 2003).

Figura 3 - Médias dos resultados do atributo aroma.
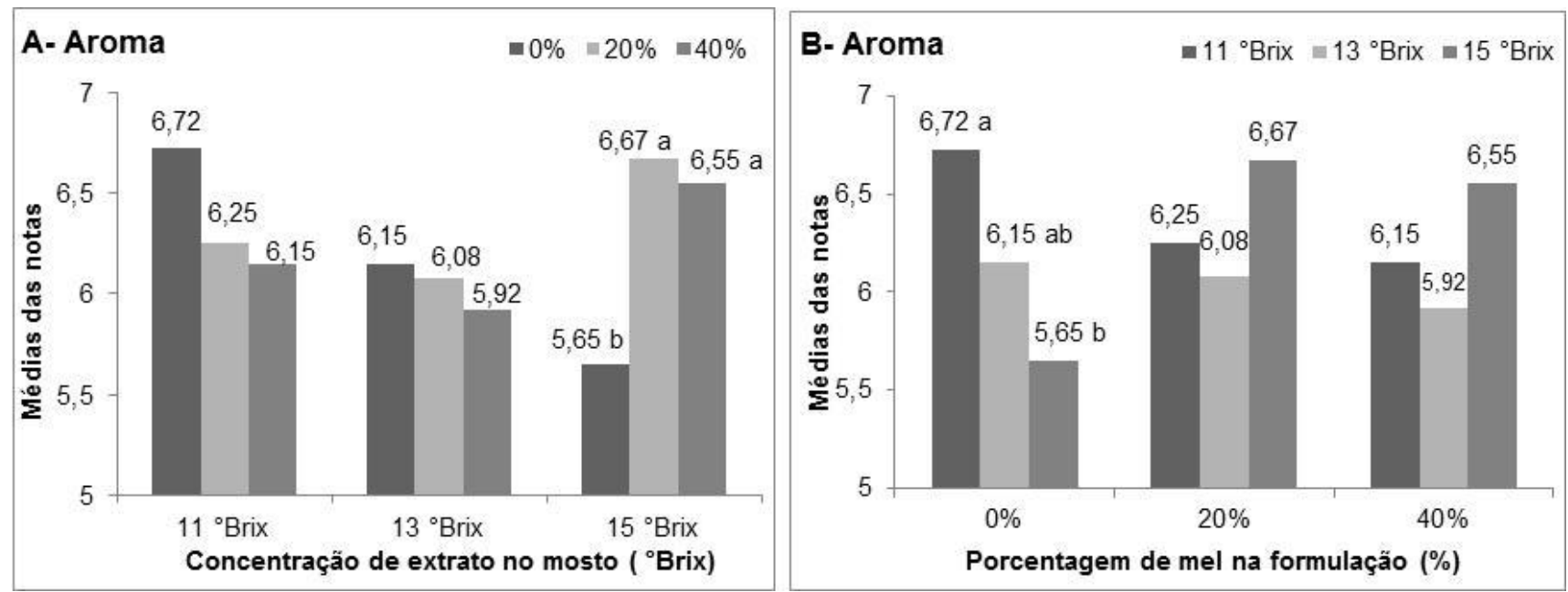

A- comparação das médias da porcentagem de mel na formulação dentro do nível de concentração de extrato no mosto. B - comparação das médias de concentração de extrato no mosto dentro do nível da porcentagem de mel na formulação

\section{Atributo Sabor}

Apenas a adição de mel interferiu no sabor da bebida $(\mathrm{p}=0,0016)$ (Tabela 2). A média das notas para o atributo sabor das cervejas elaborada com $40 \%$ mel foi maior que a das cervejas puro malte (Figura 4). Como sabor é uma interação de gosto (paladar) e aroma (olfato), é provável que as cervejas com maior concentração de mel carreguem quantidades mais elevadas de componentes de aroma dessa matéria-prima que possam ser percebidos pelos provadores, conforme já discutido no item anterior. 
Figuras 4 - Médias dos resultados do sabor em relação à porcentagem de mel

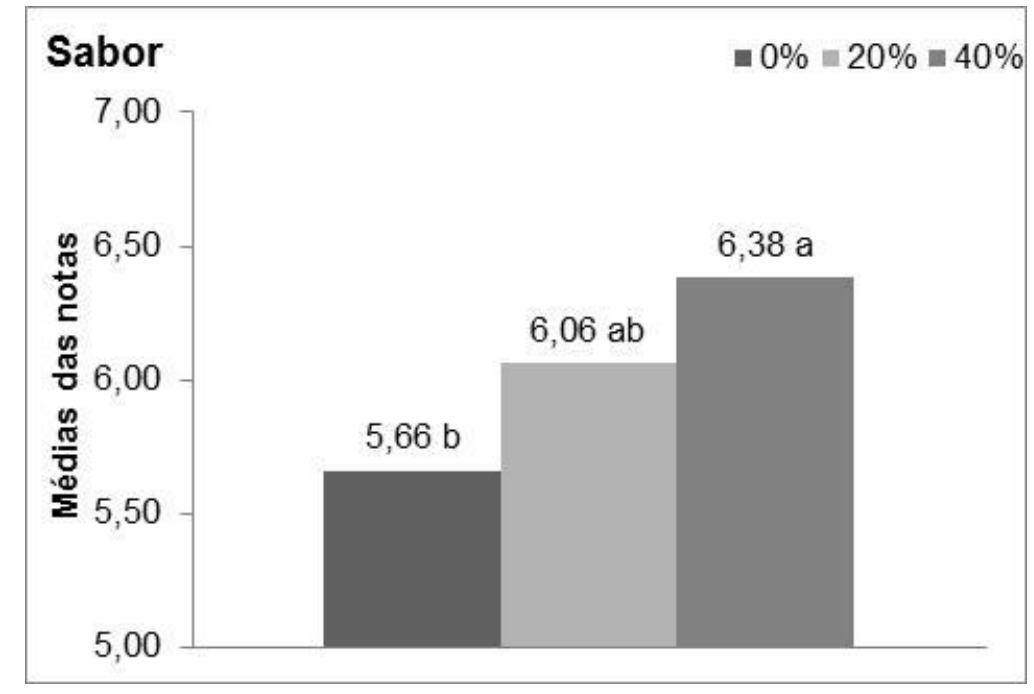

\section{Atributo Avaliação Global}

A adição de mel interferiu significativamente no atributo avaliação global das cervejas ( $\mathrm{p}=$ 0,0148) (Tabela 2). Os provadores preferiram as cervejas produzidas com $40 \%$ de mel (Figura 5). O efeito da concentração do mosto não foi significativo para este atributo.

Figuras 5 - Médias dos resultados da avaliação global em relação à porcentagem de mel

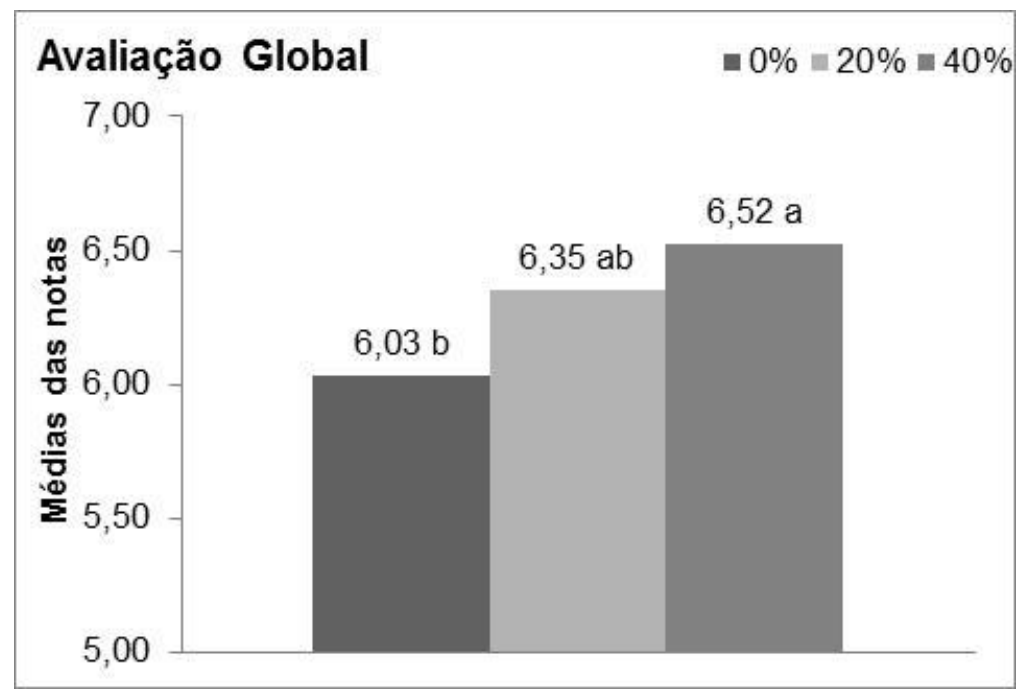

A interação entre as diferentes porcentagens de mel na formulação das cervejas e as diferentes concentrações de extrato no mosto foi significativa para este atributo avaliado ( $\mathrm{p}=$ 0,047). Desse modo, efetuou-se a análise do desdobramento da porcentagem de mel dentro de cada 
nível da concentração do mosto e a análise do desdobramento da concentração do mosto dentro de cada nível da porcentagem de mel.

O efeito da concentração do mosto dentro das diferentes proporções de mel não foi significativo para o atributo avaliação global.

O efeito da porcentagem de mel na avaliação global das cervejas apenas foi significativo nas cervejas fortes para esse atributo sensorial $(\mathrm{p}=0,0008)$. As cervejas fortes (Figura 6-A) elaboradas com mel foram as preferidas pelo painel de provadores. Esse resultado está em concordância com aqueles dos atributos sabor e aroma, evidenciando a importância dos compostos aromáticos do mel na qualidade sensorial das cervejas. Mais uma vez, a preferência recaiu para as bebidas com maiores proporções de mel em sua composição.

Figuras 6 - Média dos resultados do atributo avaliação global.
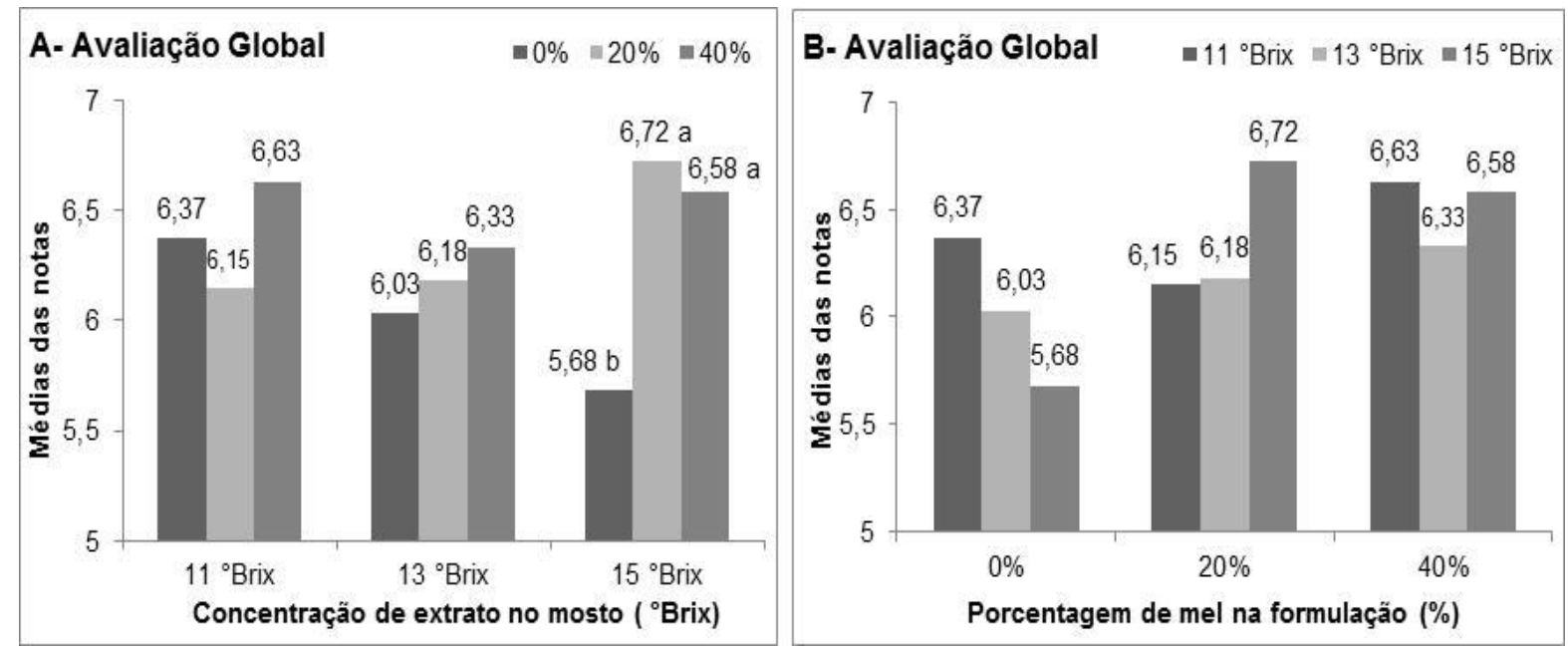

A - comparação das médias da porcentagem de mel na formulação dentro do nível concentração de extrato no mosto. B - comparação das médias de concentração de extrato no mosto dentro do nível da porcentagem de mel na formulação

Nas cervejas fortes, cujo teor de extrato, e consequentemente a concentração de componentes do mel, está acima daqueles encontrados nas cervejas comuns e extras, os compostos voláteis de sabor e aroma do mel puderam ser percebidos pela equipe sensorial (Figura 6-A). Neste caso, os provadores demonstraram maior aceitação pelas cervejas com mel em sua composição, indicando que cervejas elaboradas com essa matéria-prima devem apresentar teores de extrato primitivo de 13 a 15\%, como sugerido por Kunze (2006). 


\title{
4 Conclusão
}

Todas as cervejas foram aprovadas pela equipe sensorial, sendo que a presença de mel na formulação das cervejas comuns $\left(11^{\circ}\right.$ Brix $)$ e extra $\left(13^{\circ}\right.$ Brix $)$ não interferiu na aceitação dos provadores para todos os atributos sensoriais avaliados. Entretanto, as cervejas fortes $\left(15^{\circ} \mathrm{Brix}\right)$, com mel em sua composição, obtiveram maior aceitação dos provadores.

\section{Agradecimentos}

FAPESP - Processo 2009/11632-2.

\begin{abstract}
The aim of this study was produce and analyze through sensory analysis beer made with honey as malt adjunct. Treatments were based in a $3 \times 3$ factorial derived from the combination of three concentrations of original extract $\left(11,13\right.$ and $15^{\circ}$ Brix) and three percentages of honey in the wort (0, 20 and 40\%). The mashing process was conducted by the infusion process, and then added honey during the boiling step. After clarified, the extract contests of the wort was adjusted and bottom-fermenting yeast was inoculated in that. Fermentation occurred at $10{ }^{\circ} \mathrm{C}$. Beer was manually bottled and stored in a freezer at the temperature of $0{ }^{\circ} \mathrm{C}$ for 15 days for their maturation. The sensory analysis was accomplished through the test of structured hedonic scale of nine points. The sensory attributes analyzed were appearance, aroma, flavor and global evaluation. The results for each attribute, were subjected to variance analysis for completely randomized experiment. All beers elaboratewere approved by the team sensory, and the presence of honey in the formulation of common beers $\left(11^{\circ}\right.$ Brix) and extra (13 ${ }^{\circ}$ Brix) did not affect the acceptance of tasters for all sensory attributes evaluated. However, the strong beers with honey in its composition had higher acceptance of tasters.
\end{abstract}

Key-words: Alcoholic beverage, Hedonic scale, Acceptance testing.

\section{Referências}

ARAÚJO, F. B; SILVA, P. H. A; MINIM, V. P. R. Perfil sensorial e composição físico-química de cervejas provenientes de dois segmentos do mercado brasileiro. Ciência e Tecnologia de Alimentos, Campinas, São Paulo, v. 2, n. 23, p. 121 - 128, 2003. http://dx.doi.org/10.1590/S0101-20612003000200004

ASSOCIAÇÃO BRASILEIRA DE NORMAS TÉCNICAS. NBR 12994: métodos de análise sensorial de alimentos e bebidas. Rio de Janeiro, 1993.2 p.

BEHRENS, J. Análise sensorial de bebidas. In: VENTURINI FILHO, W. G. (Coord.). Indústria de bebidas: inovação, gestão e produção. São Paulo: Blucher, 2011. cap. 9, p. 183-213.

BRASIL. Ministério da Agricultura, Pecuária e Abastecimento. Decreto n ${ }^{\circ}$ 6.871, de 04 de junho de 2009. Regulamenta a Lei $n^{\circ}$ 8.918, de 14 julho de 1994. Dispõe sobre a padronização, a classificação, o registro, a inspeção, a produção e a fiscalização de bebidas. Diário Oficial da República Federativa do Brasil, Brasília, DF, 5 jun. 2009. Disponível em: <http://gpex.aduaneiras.com.br/gpex/gpex.dll/infobase/atos/decreto/decreto6871_09/dec\%2006871_09_01.pdf>. Acesso em: 20 nov. 2011.

BRASIL. Ministério da Saúde. Agência Nacional de Vigilância Sanitária. Métodos físico-químicos para análise de alimentos. 4. ed. Brasília, DF, 2005. 1018 p. 
BREJAS. Fuller's organic honey dew. 2008a. Disponível em: <http://www.brejas.com.br/cervejas/inglaterra/FullersOrganic-Honey-Dew/>. Acesso em: 16 dez. 2011.

BREJAS. K. M. 2008b Disponível em: <http://www.brejas.com.br/cervejas/chile/kunstmann-miel/>. Acesso em: 16 dez. 2011.

BRUNELLI, L. T. Produção de cerveja com mel: características físico-químicas, energética e sensorial. $2012.90 f$. Dissertação (Mestrado em Agronomia/Energia na Agricultura)-Faculdade de Ciências Agronômicas, Universidade Estadual Paulista, Botucatu. 2012.

CRANE, E. O livro do mel. 2. ed. São Paulo: Nobel, 1987. 226 p.

DUTCOSKY, S. D. Análise sensorial de alimentos. 3. ed. Curitiba: Champagnat, 2011. 426 p.

DRAGONE, G.; ALMEIDA E SILVA, J. B. Cerveja. In: VENTURINI FILHO, W. G. (Coord.). Bebidas alcoólicas: ciência e tecnologia. São Paulo: Blucher, 2010. cap. 2, p. 15-50.

FERREIRA, D.F. SISVAR: A computer statistical analysis system. Ciência e Agrotecnologia, Lavras, Minas Gerais, v.35, n.6, p. 1039-1042, 2011.

HUDSTON, H. R. Ebullicion del mosto. In: BRODERICK, H. M. El cervecero en la practica. Lima: Associación Latinoamericana de Fabricantes de Cerveza, 1977. cap. 7, p.150-186.

KUNZE, W. La cerveza terminada. In: Tecnología para cerveceros y malteros. Berlín: VLB Berlin, 2006. cap. 7 , p. 826-885.

RODRIGUES, M. I.; IEMMA, A. F. Noções sobre experimentos fatoriais. In: . Planejamento de experimentos \& otimização de processo. 2. ed. Campinas: Casa do Espírito Amigo Fraternidade Fé e Amor, 2009. cap. 3, p. 95-124.

SMITH, B. Brewing beer with Honey. Beer Smith Home brewing blog, 2009. Disponível em <http://www.beersmith.com/blog/2009/09/05/brewing-beer-with-honey/>. Acesso em: 8 nov. 2011.

SOARES, N. Tempo de mudança. Engarrafador Moderno, São Caetano do Sul, n. 205, p. 14-22, 2011. Disponível em: <http://www.engarrafadormoderno.com.br/edicoes/Edicao_205.pdf>. Acesso em: 15 nov. 2011.

VIERA, S. Experimentos fatoriais. In: 120-136. . Análise de variância: ANOVA. São Paulo: Atlas, 2006. cap. 10, p.

Submetido em 27 fev. 2014, Aceito para publicação em 23 jun. 2014, Publicado em 28 dez. 2014. 